Maria Raquel de Carvalho

\title{
Sincronização da Atividade Locomotora em Robalos Juvenis (Centropomus parallelus e C. undecimalis) pelo Ciclo Claro/Escuro e Ciclo de Disponibilidade
} Alimentar

\begin{abstract}
Tese apresentada ao Instituto Oceanográfico da Universidade de São Paulo, como parte dos requisitos para obtenção do Título de Doutor em Ciências, área de Oceanografia Biológica
\end{abstract}

Orientador:

Prof. Dr. Luiz Menna-Barreto 
Universidade de São Paulo

Instituto Oceanográfico

\title{
Sincronização da Atividade Locomotora em Robalos Juvenis (Centropomus parallelus e C. undecimalis) pelo Ciclo Claro/Escuro e Ciclo de Disponibilidade Alimentar
}

\author{
Maria Raquel de Carvalho
}

Tese apresentada ao Instituto Oceanográfico da Universidade de São Paulo, como parte dos requisitos para obtenção do título de Doutor em Ciências, área de Oceanografia Biológica.

Julgada em

Prof. Dr.

Conceito

Prof. Dr.

Conceito

Prof. Dr.

Conceito

Prof. Dr.

Conceito

Prof. Dr.

Conceito 


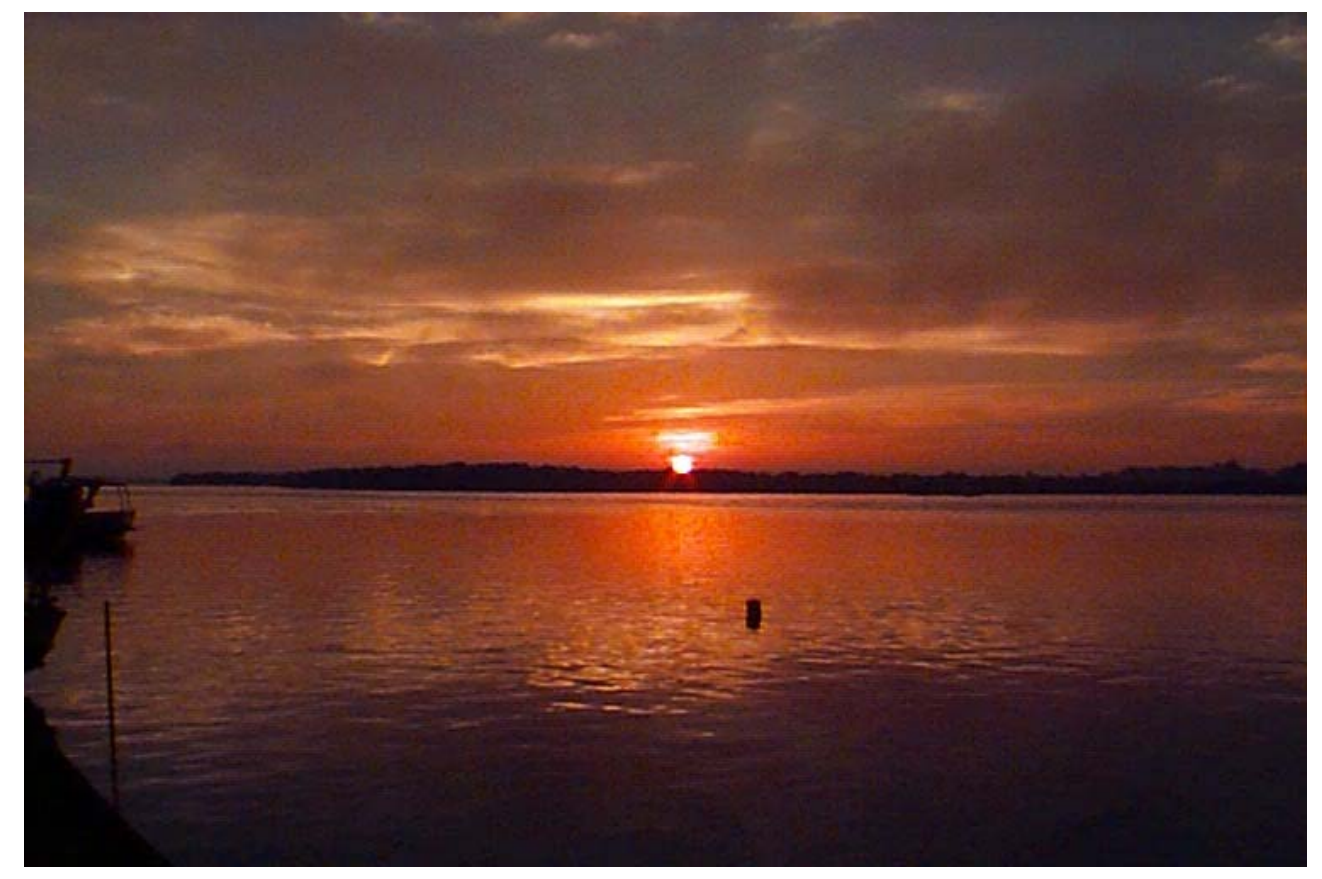

Pôr-do-sol em Cananéia - maio de 2003

Não me iludo

Tudo permanecerá do jeito que tem sido

Transcorrendo

Transformando

Tempo e espaço navegando em todos os sentidos

Tempo Rei - Gilberto Gil 
Aos meus pais, Cidinha e Nélio,

que nunca param de aprender...e sempre têm tanto para me ensinar. 
Ao GMDRB (Grupo Multidisciplinar de Desenvolvimento e Ritmos Biológicos)

Este trabalho foi desenvolvido por um grupo profissional e participativo.

Palavras como cooperação e respeito resumem o funcionamento deste grupo formado por pessoas com sentimentos raros, ideais e atitudes firmes. Cada uma destas pessoas tem a capacidade de contribuir com geração de conhecimento responsável e ensinar o que é aprendido com a mesma responsabilidade. A lição de convivência desses anos estará sempre incorporada aos meus sonhos e planos. 